\title{
O QUE É SER UM BOM PROFESSOR? ANÁLISE DAS COMPETÊNCIAS DOCENTES PELA ÓTICA DISCENTE
}

\section{WHAT IS IT TO BE A GOOD TEACHER? ANALYSIS OF TEACHING COMPETENCIES BY STUDENTS}

0 artigo foi aprovado e apresentado no XL Encontro da ANPAD (EnANPAD 2016), realizado de 25/09 a 28/09 de 2016, na Costa do Sauípe (BA)

\section{RESUMO}

A presente pesquisa visou analisar quais competências são consideradas importantes no perfil de um bom professor de Contabilidade na ótica discente. Para tanto, a amostra contou com 80 estudantes do curso de Ciências Contábeis e 100 do curso de Economia Empresarial e Controladoria da Faculdade de Administração, Economia e Contabilidade de Ribeirão Preto. A estratégia de pesquisa utilizada foi um levantamento, cujos dados foram coletados por meio de um questionário desenvolvido por Pereira (2007) e validado por Kühl et al (2013). O instrumento de coleta é composto por questões relacionadas ao perfil do respondente e por 21 assertivas avaliadas por meio de uma escala Likert de cinco pontos. Os dados obtidos foram analisados por meio de estatística descritiva e análise fatorial. Os resultados apontam que na visão dos discentes os atributos mais importantes para um bom docente de contabilidade são: ter clareza na exposição dos conteúdos; domínio sobre os conhecimentos específicos, ser ético e comprometido. Pela análise fatorial verificou-se seis fatores explicativos: "ajudar" e "aplicação" foram os que apresentaram maior porcentagem da variância explicada, indicando a importância da disponibilidade e interesse do docente em ajudar, seguido do fato de ter a experiência em utilizar em sala de aula exemplos concretos de aplicações práticas dos conhecimentos teóricos. Assim, torna-se evidente a necessidade do aperfeiçoamento da prática docente, uma vez que identificar as competências de um bom professor pode auxiliar em seu processo formativo.

Palavras-chave: competências docentes; ensino contábil; ensino superior.

\begin{abstract}
This research aimed to analyze which competences are considered important in the profile of a good Accounting teacher in the student optics. For this, a sample was used of 80 Accounting Sciences students and 100 Business Economy and Controllership students of Ribeirão Preto's School of Administration, Economy and Accounting. The research strategy used was a survey, whose data were collected through a questionnaire developed by Pereira (2007) and validated by Kühl et al (2013). The collection instrument is composed of questions related to the respondents profile and by 21 assertives evaluated using a five-point Likert scale. The data were analyzed through descriptive statistics and factorial analysis. Results show that in the students' point of view, the most important attributes for a good accounting teacher are: having clarity in the content exposition; having specific knowledge, being ethical and committed. Factor analysis revealed six explanatory factors. "helping" and "application" presented the highest percentage of explained variance, indicating the importance of the teacher's availability and willingness to help, followed by using real examples of practical applications of theoretical knowledge. Thus, the need to improve the teaching practice becomes evident, since identifying good teaching skills can help in a teacher training process.
\end{abstract}

Keywords: Teaching Skills; Accounting Education; Higher Education.

\section{Raíssa Silveira de Farias}

Doutoranda e Mestre em Controladoria e Contabilidade pela Faculdade de Economia, Administração e Contabilidade da Universidade de São Paulo, campus Ribeirão Preto (FEARP-USP) Graduada em Licenciatura pelo Programa Especial de Graduação de Formação de Professores para a Educação Profissional e em Ciências Contábeis pela Universidade Federal de Santa Maria (UFSM). Contato: Avenida dos Bandeirantes, 3900 - Monte Alegre, Ribeirão Preto, SP, CEP: 14.040-905. E-mail: farias.issa@usp.br

\section{João Paulo Resende de Lima}

Bacharel em Ciências Contábeis e Mestre em Controladoria e Contabilidade pela FEA-RP/USP. Doutorando em Controladoria e Contabilidade pela FEA/USP na linha de "Ensino e Pesquisa em Contabilidade". Integrante do Núcleo FEA de Pesquisa em GÊNEro, RAça e Sexualidade (GENERA) e Núcleo de Pesquisas e Estudos em Controle Gerencial (NUPECON ESAN/UFMS). Contato: Av. Prof. Luciano Gualberto, 908, Sala 105c - $1^{\circ}$ andar - FEA3, Cidade Universitária, São Paulo - SP. E-mail: jp.resendelima@hotmail.com

\section{Elisabeth de Oliveira Vendramin}

Doutora e Mestre em Controladoria e Contabilidade pela Universidade de São Paulo. Especialista em Gestão Estratégica de Recursos Humanos pela UNIDERP. Graduada em Ciências Contábeis pela Faculdade de Ponta Porã. Graduada em Administração de Empresas pela UNIGRAN. Docente da Escola de Administração e Negócios (ESAN) na Universidade Federal de Mato Grosso do Sul (UFMS). Contato: Av. Senador Filinto Muller, 1555 - Unidade 10, Campo Grande, MS, CEP: 79.074-460. E-mail: elisabeth. vendramin@ufms.br

\section{Adriana Maria Procópio de Araújo}

Professora Titular da Universidade de São Paulo e Livre Docente pela mesma Instituição. Mestre e Doutora em Contabilidade e Controladoria pela FEARP-USP. Pós doutora em Educação pela UFSCar e pelo College off Law, University of Illinois. Graduada em Administração e em Ciências Contábeis. Docente do Departamento de Contabilidade da FEARP-USP. Contato: Av. dos Bandeirantes, 3900- Monte Alegre, Ribeirão Preto, SP, Cep 14040-409. E-mail: amprocop@usp.br

\section{Roselaine Ruviaro Zanini}

Doutora em Epidemiologia pela Universidade Federal do Rio Grande do Sul (UFRGS). Mestre em Engenharia de Produção e Especialista em Estatística e Modelagem Quantitativa pela Universidade Federal de Santa Maria (UFSM). Graduado em Matemática pela Faculdade Imaculada Conceição (FIC). Docente do Departamento de Estatística da Universidade Federal de Santa Maria (UFSM). Contato: Avenida Roraima, 1000, Prédio 13 (CCNE), Santa Maria, RS, CEP: 97.105-900. E-mail: rrzanini@smail.ufsm.br 


\section{INTRODUÇÃO}

A docência, assim como todas as profissões, requer formação profissional, demanda por saberes, competências e habilidades próprias para o seu ofício. Conforme esclarece Slomski (2008), um dos papéis do professor é aperfeiçoar sua profissão a partir do domínio de saberes, aquisição de competências e aperfeiçoamento de habilidades para agir individual e coletivamente no exercício da mesma.

O professor é peça-chave no processo de ensino-aprendizagem e no desenvolvimento de qualquer programa acadêmico. Possui grande responsabilidade em seu trabalho: desenvolver conhecimentos, habilidades e atitudes, e dotar o aluno de competência visando o seu sucesso profissional (OTT et. al, 2011).

O ensino contábil no Brasil apresenta um cenário de crescimento da oferta dos cursos de graduação nos últimos anos, e em consequência, a expansão do número de vagas para docentes do ensino superior. De acordo com o Instituto Nacional de Estudos e Pesquisas Educacionais Anísio Teixeira (INEP), o cenário de expansão dos cursos de Ciências Contábeis mostra que em 2000 existia 235 cursos de graduação, passados 16 anos, este número aumentou para 1.247 (INEP, 2001; 2017). Conforme dados apontados pelo mesmo instituto no período de 2009 a 2016, o número de docentes dos cursos de Ciências Contábeis aumentou em 24,68\%, passando de 21.908 em 2009 para 27.314 em 2016.

Essa pesquisa tomará como foco a formação do docente que atua nos cursos de Ciências Contábeis no Brasil, em função do fundamental papel que este exerce na formação dos futuros profissionais da área. Para tanto, faz-se necessário ao docente de contabilidade conhecimentos teóricos, estruturais, didáticos e pedagógicos; além dos conhecimentos e das habilidades técnicas exigidas pela profissão de contador (ANDERE; ARAUJO, 2008). A necessidade de formação didático-pedagógica não descarta a importância dos conhecimentos específicos, porém ser contador não significa já estar formado para o ensino, conforme afirma alerta Miranda (2010).

Estudos vêm sendo realizados ao longo dos anos com o intuito de identificar quais as características de um bom professor sob a ótica discente e do próprio docente (LOWMAN, 2007; PAN et. al, 2009), inclusive de forma mais específica no âmbito do ensino contábil (SWAIN; STOUT, 2000; GOMES et. al, 2009; CATAPAN; COLAUTO; SILAS, 2012; REZENDE; LEAL, 2013; TOLENTINO et. al, 2014; REZENDE et. al, 2015; BOULEY, et al. (2015)). O presente artigo justifica-se com base na premissa de que "o perfil de um bom professor para determinado público pode não ser igual para outro”, conforme afirma Nogueira, Casa Nova, Carvalho (2012, p. 38).

Dessa forma, buscou-se nesse artigo o estudo de público-alvo diverso daquele apresentado na literatura, de acordo com características próprias (gênero, idade, cultura, etc.), a fim de contribuir com os estudos na área e obter a convergência dos resultados, uma vez que identificar as competências de um bom professor pode auxiliar em seu processo formativo, e consequentemente, no processo ensino-aprendizagem de seus alunos.

Nesse sentido, o presente estudo visou analisar quais competências são consideradas mais importantes no perfil de um bom professor de Contabilidade na ótica discente a partir da percepção de alunos dos cursos de Ciências Contábeis e Economia Empresarial e Controladoria (ECEC) da Faculdade de Administração, Economia e Contabilidade de Ribeirão Preto, da Universidade de São Paulo (FEA-RP/USP) e é norteado pela seguinte pergunta: quais competências são consideradas mais importantes no perfil de um bom professor de Contabilidade na ótica discente?

Para o alcance desse propósito, foi realizado um estudo descritivo, cuja estratégia de pesquisa utilizada foi um levantamento no qual o instrumento de coleta de dados foi um questionário estruturado, desenvolvido por Pereira (2007) e validado por Kühl et. al (2013), composto por vinte e uma questões sobre o objeto de estudo, as quais foram respondidas por meio de uma escala Likert de cinco pontos. Os dados foram analisados a partir de uma análise descritiva, bem como da aplicação da análise fatorial.

Do ponto de vista prático, o estudo poderá auxiliar as instituições formativas, como Programas de Pós-graduação e Instituições de Ensino Superior, a promover ações que integrem as competências consideradas importantes na formação didático-pedagógica de seus alunos e professores. Além disso, poderá auxiliar os próprios professores a identificar as lacunas percebidas em sua formação para a docência, quanto às competências consideradas importantes para conduzir uma carreira como um bom professor de Ciências Contábeis. A reflexão sobre sua prática e suas competências podem ser consideradas oportunidades para melhorar o processo de desenvolvimento do profissional docente, e consequentemente, o processo de ensino-aprendizagem.

Este estudo está estruturado em cinco seções. Após a introdução ora apresentada, aborda-se o referencial teórico, onde se encontram as teorias e fundamentos que deram suporte à análise dos resultados. Na terceira seção, descrevem-se os procedimentos metodológicos utilizados para realização do estudo. Em seguida, são apresentados os resultados encontrados e as respectivas discussões. E, por último, as considerações finais a respeitos dos achados do trabalho.

\section{REFERENCIAL TEÓRICO}

Nessa seção discorre-se sobre as competências necessárias para a prática docente, bem como sobre as características do "bom professor" e os estudos relacionados a esse conceito na área contábil.

\subsection{Competências Docentes}


Competências assumem um papel de destaque na pesquisa em educação no nível nacional e internacional (DIAS, 2010). O termo “competência”, relacionado à docência é conceituado por Braslavsky (1999, p. 13) como sendo “a capacidade de fazer com saber e com consciência sobre as consequências desse saber. Toda competência envolve, ao mesmo tempo, conhecimentos, modos de fazer, valores e responsabilidades pelos resultados de aquilo que foi feito". Perrenoud (2000, p. 15), por sua vez, compreende competência como a "capacidade de mobilizar diversos recursos cognitivos para enfrentar um tipo de situação".

Masetto (2012) contribui ao apresentar as competências necessárias à docência, abrangendo-as em três aspectos: (1) competência em uma área específica, a qual compreende um domínio dos conhecimentos básicos em determinada área, bem como experiência profissional de campo; (2) competência na área pedagógica que, na percepção do autor é "o ponto mais carente dos professores universitários, quando se fala em profissionalismo na docência” (MASETTO, 2012, p. 32), e abrange o domínio do conceito de processo de ensino-aprendizagem, concepção e gestão de currículo, interligação das disciplinas como componentes curriculares, compreensão da relação professor-aluno e aluno-aluno, teoria e prática da tecnologia educacional, concepção do processo avaliativo e suas técnicas para feedback, planejamento como atividade educacional e política; e (3) competência na área política, uma vez que professor e aluno são cidadãos e carregam consigo suas visões de homem, de mundo, de sociedade, de cultura, de educação.

Kühl, et al. (2013) realizaram um estudo, no qual apontam cinco competências docentes consideradas importantes no exercício da docência, a partir do levantamento de vinte e uma variáveis representativas desses cinco constructos, conforme Quadro 1.

\section{Quadro 1 - Competências requeridas à docência}

\section{Competências dos docentes}

1. Didática: "associa-se ao conjunto de atividades ligadas à transmissão direta do conhecimento do educador ao educando" (GRADVOHL; LOPES; COSTA, 2009, p. 3). Dentre as características que compõem a didática estão: a clareza (Did01) na apresentação dos conteúdos; a proposição e manutenção da dinâmica (Did02) de aprendizagem com a presença ativa do discente; a utilização de técnicas e atividades práticas (Did03) para facilitar o aprendizado, fazendo uso de instrumentalização técnica; a capacidade de interligação (Did04) do conteúdo com outras disciplinas da grade curricular (GRADVOHL; LOPES; COSTA, 2009; PLUTARCO; GRADVOHL, 2010).

2. Conhecimento: "[...] conjunto de informações adequadas e estruturadas pelo indivíduo, responsáveis pela forma como o mesmo enxerga as ações, as pessoas, os conceitos, as relações entre os sujeitos e realidade que ele vive" (MEDEIROS; OLIVEIRA, 2009, p. 5). Dentre as características que compõem o conhecimento estão: o conhecimento prático (Conh01), baseado mais na experiência que no ensino formal; o conhecimento específico (Conh02), que são os conhecimentos básicos em uma área; conhecimento amplo (Conh03) da área da disciplina ou das disciplinas do curso, integrando com outras áreas de estudo (GRADVOHL; LOPES; COSTA, 2009; PLUTARCO; GRADVOHL, 2010); e o conhecimento geral (Conh04), o que ajuda na compreensão de diversos aspectos relacionados ao ensino e facilita a transmissão de conteúdo específicos.

3. Experiência: pode ser adquirida a partir da prática profissional, denominada experiência desvinculada (Exp01), porém não relacionada com as disciplinas, ou seja, àquela atividade desvinculada da área de conhecimento/atuação profissional do (s) curso(s) aos quais está vinculado o docente (KÜHL et. al, 2013); experiência adquirida em atividades externas relacionada às disciplinas, denominada experiência vinculada (Exp02); competência relacionada à capacidade de aproximar teoria e prática, referida como aproximação (Exp03); e a utilização e aplicação, em sala de aula, exemplos da realidade, denominada aplicação (Exp04).

4. Relacionamento: definido como a prática da busca do respeito mútuo, do relacionamento interpessoal entre docente e discente e entre discentes. No conjunto de competências de relacionamento do docente está incluída a tolerância (Rel01), ou seja, a capacidade de se colocar na posição do discente, tendo empatia no trato das questões relacionadas aos acadêmicos; ser acessivel (Rel02), ter a capacidade de proporcionar abertura à discussão e à reflexão do tema que está sendo abordado; disponibilidade e interesse em ajudar (Rel03) o discente em sua formação, possibilitando uma aproximação contínua; e flexibilidade (Rel04) do docente, que "é a capacidade de adaptar-se a novas situações e de rever posturas quando necessário na sua atuação no processo de ensino-aprendizagem" (PEREIRA, 2007, p. 136).

5. Postura: definida por Pereira (2007) como "[...] o saber comportamental, relacionado com a disposição de um indivíduo de querer fazer alguma coisa, normalmente ligado a aspectos do campo social ou afetivo". Dentre os atributos desta competência estão a ética (Post01), "comportamento orientado por princípios e valores universais de cidadania, em especial na relação com seus alunos" (PEREIRA, 2007, p. 85); comprometimento (Post02), do docente "[...] com a obtenção de resultados positivos nas atividades de ensino sob a sua responsabilidade” (MEDEIROS; OLIVEIRA, 2009, p. 12); organização (Post03), atributo de organizar sequência lógica das atividades de cada aula lecionada pelo docente (MEDEIROS; OLIVEIRA, 2009), sendo o papel do docente a "[...] capacidade de planejar e organizar as diversas atividades do processo ensino-aprendizagem" (PEREIRA, 2007, p.

130); Proatividade (Post04) atuação autônoma do docente, sem supervisão direta. Para Pereira (2007, p. 134), "é o comportamento relacionado ao ato de praticar ações concretas por iniciativa pessoal para aprimorar o processo ensino-aprendizagem"; ser comunicativo (Post05), competência que inclui "[...] voz, linguagem corporal e as palavras como falar, cantar e, por vezes, o tom de voz, linguagem gestual, paralinguagem, toque, contato visual, ou o uso da escrita. Elas incluem as habilidades de comunicação no processamento intrapessoal e interpessoal, ouvir, observar, falar, questionar, analisar e avaliar" (SELVI, 2010, p. 171-172). 
O processo de ensino e aprendizagem exige compromisso dos três principais agentes deste processo: instituição de ensino, professor e aluno. A fim de desenvolver um ensino de qualidade, esse processo envolve múltiplas competências dos docentes em sua prática. No próximo tópico apresentam-se as características apontadas em estudos empíricos do bom professor de contabilidade.

\subsection{Estudos Anteriores}

Após discorrer sobre as competências necessárias à docência, nesse tópico serão expostos alguns estudos empíricos sobre as principais características de um "bom professor" de contabilidade, a fim de refletir sobre o aperfeiçoamento da prática docente a partir da percepção de docentes e discentes.

Ressalta-se que, o conceito de "bom professor" é subjetivo, e como tal, carrega em si uma crítica comum ao olhar científico, incluso na definição do adjetivo "bom". Independentemente dessa crítica, trata-se de um conceito com importantes implicações pedagógicas (MARQUES et. al, 2012). Cunha (1992) assevera não ter definições próprias do bom professor, sendo as características e/ou atributos que compõem a ideia de bons frutos do julgamento individual. $\mathrm{O}$ aluno faz a sua própria construção de bom professor, mas essa construção está localizada em um contexto histórico-social e, por isso, não é fixa, modificando-se conforme as necessidades dos seres humanos situados no tempo e no espaço.

Segundo Pimenta (1997), ser bom professor é uma identidade em permanente construção, que adquire significados conforme os contextos, os momentos histórico-sociais e pessoais, os valores e as finalidades que a sociedade, o professor e os alunos atribuem à educação. Amaral (2010) define "bom professor" como um pesquisador em sua área de conhecimento que tenha ao mesmo tempo capacidade de transmitir a síntese do conhecimento acumulado até então, e ensinar. O professor deve ser capaz de "auxiliar os alunos na transformação de informações em conhecimento" (AMARAL, 2010, p. 28).

No contexto do ensino superior, de forma geral, Torra et al. (2012) realizaram um estudo com o objetivo de identificar as competências mais valorizados por 2.029 professores de oito universidades públicas do Catalão. O processo de identificação das competências foi desenvolvido com base em uma revisão da literatura sobre o estado da arte, e posteriormente, por meio de grupos focais com 64 peritos, a respeito das competências necessárias aos docentes do ensino superior. Os resultados apontaram que $74 \%$ das respostas consideraram as competências comunicativa, interpessoal e metodológica como as mais importantes em um bom professor universitário.

Gomes et. al (2009) utilizaram-se do modelo bidimensional de Lowman (2007) com o objetivo de analisar os principais atributos dos professores de contabilidade que possuem êxito em sala de aula, na percepção dos alunos das Universidades Públicas do Estado da Paraíba. Os resultados apontaram que na dimensão estímulo intelectual os atributos destacados aos professores-referências foram: estar preparado, ser claro, organizado e estimular os alunos. Ou seja, na análise dos autores além do domínio dos conteúdos referente às disciplinas as quais leciona, o professor deve ter a competência e a habilidade de tornar assuntos de difícil entendimento em algo de fácil compreensão para o aluno e isto é possível desde que, "o professor tenha a consciência que existem técnicas, métodos de ensino adequados para todos os conteúdos ou objetivos propostos em um plano de curso” (GOMES et. al, 2009, p. 10).

Swain e Stout (2000), abalizados na preocupação da comissão norte-americana Accounting Education Change Commission (AECC) quanto a necessidade de ensinar professores de contabilidade sobre métodos de formação adequados ao ensino contábil, bem como as competências didático-pedagógicas a serem enfatizadas pelos programas de Pós-graduação em contabilidade, quando da formação dos futuros docentes; estudaram a percepção dos recém-doutores em contabilidade norte-americanos quanto à importância de seis competências propostas pela AECC, são elas: organizar o currículo e planejar a ação educativa; selecionar e preparar os conteúdos disciplinares; comunicar o conteúdo; dominar métodos de ensino; avaliar a aprendizagem; e orientar e aconselhar os alunos. Os autores concluem que as competências "Organização do currículo e Planejamento da ação educativa”, bem como "Comunicação do conteúdo" foram elencadas como as mais importantes; e as competências "Domínio dos métodos de ensino" e "Orientação e aconselhamento", como as menos importantes ao ensino da Contabilidade.

Em contexto distinto, Catapan, Colauto e Silas (2012) analisaram as principais práticas e atributos dos professores de contabilidade que possuem êxito em sala de aula, do ponto de vista dos discentes de universidades públicas e privadas das cidades de Curitiba (PR) e Joinvile (SC). Os resultados encontrados apontaram que as razões do bom desempenho docente foi o domínio do conteúdo e a clareza ao transmitir as informações. Os autores concluíram, ainda, no que tange às duas dimensões propostas por Lowman (2007), quando da comparação dos resultados encontrados com os achados de Gomes et al. (2009) e Celerino e Pereira (2008), que há uma proximidade entre os três estudos e que os resultados apontam para as características: ser organizado, estimulante, interessado e acessível, como sendo as características do professor exemplar.

O nível de importância dos atributos de competência do professor na percepção dos alunos de Ciências Contábeis do segundo, quinto e sétimo período de três faculdades de Belo Horizonte (MG) foi o objetivo e objeto do estudo de Marques et al. (2012). Tomando como base os atributos de competência propostos por Raldi et. al (2003), quais sejam: ter conhecimento, ser acessível, ser amigo, ter didática, ter segurança, ter titulação, ter vivência ou experiência, ser objetivo, ser rigoroso e ser bonzinho; os resultados apontaram que nível de conhecimento, didática e segurança foram as competências mais valorizados pelos alunos em um docente. Ou seja, os alunos valorizam o conhecimento detido pelo professor sobre o conteúdo da disciplina, e esperam que o professor tenha habilidade para ensinar. A segurança como terceiro atributo de destaque está estritamente ligada ao nível de conhecimento e à didática, pois segundo afirmam os 
autores "professores com maior nível de conhecimento tendem a possuir alto nível de segurança, o que contribui substancialmente ao aprendizado dos alunos na medida em que eles também terão segurança no conhecimento transmitido" (MARQUES et. al, 2012, p. 19).

Rezende e Leal (2013) desenvolveram um estudo com discentes, dos três últimos períodos de graduação do curso de Ciências Contábeis de instituições de ensino pública e privada, localizadas em Uberlândia-MG. O objetivo foi avaliar o grau de importância atribuída às competências docentes, na perspectiva dos discentes, bem como identificar as competências requeridas para os docentes desse curso. Os autores, a partir de um levantamento da literatura, listaram, para a análise dos estudantes, doze competências: didática, relacionamento, exigência, conhecimento teórico, experiência de mercado, flexibilidade, criatividade, comunicação, liderança, planejamento, comprometimento e empatia. Os resultados apontaram que as competências que possuem maior relevância estão relacionadas ao domínio do conhecimento, à didática e à experiência de mercado.

Tolentino et. al (2014), por sua vez, identificaram a percepção de 127 alunos de uma instituição de ensino localizada na Cidade de Barcelos, no distrito de Braga em Portugal, quanto à competência necessária ao bom professor. O instrumento de coleta de dados utilizado pelos autores buscou mensurar a importância de cinco competências, atribuídas pelos alunos aos docentes, combinados de maneira a formar doze perfis distintos. Os autores concluíram que, para os estudantes, as competências mais importantes são: didática, exigência, conhecimento teórico, relacionamento e experiência de mercado. Já, quanto ao perfil, um bom professor, no julgamento dos respondentes, é aquele docente que possui uma boa didática, um próximo relacionamento com os alunos, muita experiência de mercado, pouca exigência e amplo conhecimento teórico.

Rezende et. al (2015) avaliaram as competências pedagógicas dos docentes de cursos de Master's in Business Administration (MBA) de uma universidade pública brasileira, a partir da percepção de 116 estudantes de pós-graduação (MBAs) na área de negócios. Para tanto, solicitaram a análise de 22 competências didáticas, quais sejam: domínio de conteúdo, explicação do conteúdo, uso de recursos didáticos, motivação dos alunos, apresentação da matéria, didática, atitude de superioridade, explicação dos exercícios, interação com os alunos, variação da metodologia, seleção dos conteúdos, interesse pela aula, insegurança na explicação, comunicação com os alunos, clareza na explicação do conteúdo, domínio da classe, respostas às perguntas dos alunos, cumprimento do horário de aula, e critérios de avaliação. Os resultados apontaram que as competências levantadas são percebidas pelos respondentes em seus respectivos professores dos cursos de MBAs. Além disso, foram identificados quatro fatores, nos quais as competências pedagógicas se agruparam, são eles: competências didáticas, competência de relacionamento e interação, competência de comunicação e competência de domínio do conteúdo; todos considerados relevantes no perfil de um bom professor.

Bouley, et al. (2015) desenvolveram um estudo cujo objetivo foi testar um modelo de competência profissional para professores de contabilidade, a partir de equações estruturais. A amostra do estudo foi composta por 1.152 estudantes de 24 universidades alemãs. Os autores partem do pressuposto de que para ensinar bem, os professores necessitam de conhecimento profissional, composto de conhecimento de conteúdo, conhecimento de conteúdo pedagógico e conhecimento pedagógico. Os autores propõem um modelo de competência, o qual sugere que a competência profissional em contabilidade tem pelo menos quatro dimensões distintas, são elas: conhecimento de conteúdo, conhecimento de conteúdo pedagógico, crenças profissionais e aspectos de auto regulação.

A maior parte dos estudos elencados aponta algumas características comuns na percepção dos diversos públicos pesquisados: domínio do conhecimento, didática e experiência de mercado. No entanto, pesquisas científicas que abarquem esse tema encontram em si mesmo motivação para seguir adiante, uma vez que o perfil de um bom professor para determinado público pode não ser igual para outro (REICHEL; ARNON, 2009), o que proporciona uma série de novas investigações alterando o público-alvo de acordo com suas características (gênero, idade, cultura etc.) visando obter a convergência dos resultados (NOGUEIRA; CASA NOVA; CARVALHO, 2012).

A identificação das características (competências) de um bom professor, a partir da percepção docente e discente, auxilia no processo formativo desses e dos futuros professores como um norte, pois são aspectos que devem ser desenvolvidos nos professores, quando da sua formação inicial e continuada, como forma de aperfeiçoar sua prática docente. A partir de estudos que buscam encontrar e compreender as características do bom professor e as competências para o exercício da docência é possível "gerar informações relevantes para o planejamento da ação docente tanto de professores quanto de gestores de cursos e de instituições de formação” (GRADVOHL; LOPES; COSTA, 2009, p. 14), a fim de aperfeiçoar o processo de ensino e aprendizagem, e contribuir para a qualidade desse ensino por meio do aprimoramento do processo seletivo de novos professores.

\section{PROCEDIMENTOS METODOLÓGICOS}

O objetivo deste estudo foi analisar quais competências são consideradas mais importantes no perfil de um bom professor de Contabilidade na ótica discente a partir da percepção de alunos dos cursos de Ciências Contábeis e Economia Empresarial e Controladoria (ECEC) da Faculdade de Administração, Economia e Contabilidade de Ribeirão Preto, da Universidade de São Paulo (FEA-RP/USP). Para tanto, realizou-se um estudo exploratório-descritivo, utilizando-se como estratégia de pesquisa um levantamento, cujo instrumento para a coleta dos dados foi um questionário estruturado, desenvolvido e validado por Pereira (2007) e Kühl et. al (2013). 


\subsection{Coleta de Dados}

O questionário foi aplicado presencialmente por um dos pesquisadores a partir de um convite realizado aos alunos dos dois cursos de graduação mencionados, para que respondessem ao questionário de forma não obrigatória. A aplicação aconteceu no início das aulas de cada uma das turmas participantes, com a devida autorização do docente que estava em sala de aula. No momento da aplicação os discentes foram instruídos a avaliarem os docentes das disciplinas de Contabilidade de maneira geral e não o docente que estava em sala de aula ou de outras áreas de conhecimento. Buscou-se aplicar o questionário para o maior número de alunos e visando alcançar a diversidade no que diz respeito ao semestre do curso. Dessa forma, a amostra é composta pela percepção de 80 estudantes do curso de Ciências Contábeis e 100 do curso de Economia Empresarial e Controladoria.

O questionário foi estruturado em duas partes: na primeira os alunos responderam perguntas sobre informações pessoais e na segunda constam 21 afirmativas sobre as características de um bom professor. As afirmativas correspondem a cinco competências, quais sejam: Postura, Didática, Relacionamento, Conhecimento e Experiência, conforme Quadro 2.

Quadro 2 - Variáveis correspondentes às competências individuais do docente

\begin{tabular}{|c|c|c|c|}
\hline Constructos & Variáveis & Código & Descrição \\
\hline \multirow{4}{*}{ Didática } & Clareza & V1 & Apresentar conteúdos de forma clara e objetiva. \\
\hline & Dinâmica & $\mathrm{V} 2$ & $\begin{array}{l}\text { Utilizar formas dinâmicas de aprendizagem, que promovam a participação } \\
\text { do aluno. }\end{array}$ \\
\hline & Metodologias & V3 & $\begin{array}{l}\text { Utilizar metodologias e atividades práticas para exposição dos conteúdos } \\
\text { que facilitem a aprendizagem. }\end{array}$ \\
\hline & Interligação & V4 & Buscar interligar os conteúdos com os de outras disciplinas do curso. \\
\hline \multirow{4}{*}{ Conhecimento } & Prático & V5 & $\begin{array}{l}\text { Ter conhecimento prático baseado em experiências adquiridas fora do } \\
\text { ensino formal. }\end{array}$ \\
\hline & Específico & V6 & Possuir profundo conhecimento da disciplina em que atua. \\
\hline & Amplo & V7 & $\begin{array}{l}\text { Ter amplo conhecimento das outras disciplinas relacionadas à disciplina } \\
\text { ministrada. }\end{array}$ \\
\hline & Geral & V8 & Possuir nível elevado de conhecimento geral. \\
\hline \multirow{4}{*}{ Experiência } & Desvinculada & V9 & $\begin{array}{l}\text { Estar ou ter atuado em atividade fora da docência NÃO relacionada às } \\
\text { disciplinas ministradas. }\end{array}$ \\
\hline & Vinculada & V10 & $\begin{array}{l}\text { Estar ou ter atuado em atividade fora da docência relacionada às } \\
\text { disciplinas ministradas. }\end{array}$ \\
\hline & Aproximação & V11 & Aproximar os conteúdos teóricos ao conhecimento prático. \\
\hline & Aplicação & V12 & $\begin{array}{c}\text { Utilizar em sala de aula exemplos concretos de aplicações práticas dos } \\
\text { conceitos teóricos. }\end{array}$ \\
\hline \multirow{4}{*}{ Relacionamento } & Tolerância & V13 & Capacidade de colocar-se na posição do aluno. \\
\hline & Acessível & V14 & Ser acessível para questionamentos e discussões. \\
\hline & Ajudar & V15 & Ter disponibilidade e interesse em ajudar. \\
\hline & Flexível & V16 & Ser flexível nas relações com os alunos. \\
\hline \multirow{5}{*}{ Postura } & Ético & V17 & Demonstrar postura ética. \\
\hline & Comprometido & V18 & Demonstrar comprometimento com a atividade docente. \\
\hline & Organizado & V19 & Ser organizado nas atividades docentes. \\
\hline & Proativo & V20 & Ser proativo. \\
\hline & Comunicativo & V21 & Ser comunicativo. \\
\hline
\end{tabular}

Fonte: Kühl et. al (2013).

Para cada afirmativa os alunos deram nota de 1 a 5 (escala Likert) para o grau de importância da competência considerada relevante em um "bom professor", sendo considerado "mais relevante" quanto mais próximo de cinco. 


\subsection{Procedimentos de Análise}

Para a análise dos dados obtidos foram realizadas duas etapas de análise. Inicialmente os dados foram analisados de maneira descritiva a partir da sua distribuição de frequência relativa e absoluta. Na sequência, aplicou-se a Análise Fatorial (AF), que permite sintetizar uma grande variedade de dados, visando detectar fatores comuns (FÁVERO et at, 2009).

Antes de realizar a análise fatorial foi avaliada a consistência interna da escala (intensidade da correlação entre os itens), cujo teste utilizado para medir este estimador foi o Alfa de Cronbach, considerado, conforme Hora, Monteiro e Arica (2010) uma forma de estimar a confiabilidade de um questionário aplicado em uma pesquisa, e o mais popular e o mais usado por pesquisadores da área (PASQUALI, 2003; YU, 2001).

Após a verificação da consistência interna do questionário foram realizados dois testes para verificar a adequação da técnica estatística adotada e da amostra. Para verificar a adequada aplicação da AF foi realizado o teste de Kaiser-Meyer-Olkin (KMO), também conhecido como índice de adequação da amostra, indicando a proporção da variância explicada por uma variável latente. Além disso foi realizado o teste de esfericidade de Bartlett que indica a adequação do uso da metodologia. O teste de esfericidade de Bartlett tem como hipótese nula que a matriz de correlações é uma matriz identidade e a partir de sua rejeição tem-se evidências suficientes acerca da adequação do uso da metodologia para o presente estudo.

O método Varimax padronizado foi escolhido para a extração dos fatores e o número de fatores considerados baseou-se nos critérios do autovalor maior do que a unidade (Hair, 2005). As análises estatísticas foram realizadas com o Statistica 9.1 considerando-se um nível de significância igual a 5\%. Os parâmetros descritos até aqui (Alfa de Cronbach, KMO e Esfericidade de Bartlett) são apresentados na tabela 1.

Tabela 1 - Parâmetros da Análise Estatística

\begin{tabular}{ccc}
\hline & Parâmetro & Valor Estatístico \\
\hline KMO & Approx. Chi-Square & 0,757 \\
& df & 1310,227 \\
Teste de Esfericidade de Bartlett & Sig. & 300 \\
Alfa de Cronbach & & 0,000 \\
\hline
\end{tabular}

Fonte: dados da pesquisa.

Com base nos dados apresentados na tabela 1 percebe-se que o teste de KMO e esfericidade de Bartlett mostram a adequação da técnica para o presente estudo. Ainda na tabela 1 observa-se que o Alfa de Cronbach, de acordo com George e Malley (2003), está em um nível ótimo, demonstrando a validade interna dos dados. Uma vez explicitado a composição do questionário, o processo de coleta e análise dos dados e os parâmetros estatísticos das análises, apresenta-se na sequência os resultados encontrados.

\section{ANÁLISE DOS RESULTADOS}

\subsection{Perfil dos Respondentes}

A amostra foi composta por alunos de dois cursos pertencentes a FEARP/USP, sendo 80 estudantes do curso de Ciências Contábeis e 100 do curso de Economia Empresarial e Controladoria. Dos 180 alunos que participaram da pesquisa, $52,22 \%$ (94) pertencem ao gênero masculino, 46,11\% (83) ao gênero feminino e 1,67\% (3) não responderam a esta questão; a maioria dos alunos concentra-se na faixa etária entre 19 e 23 anos (Tabela 2); e quanto a série cursada pelos respondentes, houve participação de alunos representativos dos 5 anos (Tabela 3).

Tabela 2 - Faixa etária

\begin{tabular}{ccccc}
\hline & \multicolumn{2}{c}{ Ciências Contábeis } & \multicolumn{2}{c}{ Economia Empresarial e Controladoria } \\
\hline Idade & Fi & Fi (\%) & Fi & Fi (\%) \\
\hline Até 19 anos & 22 & $27,50 \%$ & 36 & $36,00 \%$ \\
De 20 a 25 anos & 46 & $57,50 \%$ & 62 & $62,00 \%$ \\
De 26 a 30 anos & 10 & $12,50 \%$ & 02 & $2,00 \%$ \\
Acima de 30 anos & 01 & $1,25 \%$ & 0 & $0,00 \%$
\end{tabular}




\begin{tabular}{ccccc}
\hline & \multicolumn{2}{c}{ Ciências Contábeis } & \multicolumn{2}{c}{ Economia Empresarial e Controladoria } \\
\hline Idade & Fi & Fi (\%) & Fi & Fi (\%) \\
\hline Não informou & 01 & $1,25 \%$ & 0 & $0,00 \%$ \\
TOTAL & $\mathbf{8 0}$ & $\mathbf{1 0 0 , 0 0 \%}$ & $\mathbf{1 0 0}$ & $\mathbf{1 0 0 , 0 0 \%}$ \\
\hline
\end{tabular}

Fonte: dados da pesquisa.

Tabela 3 - Série do curso

\begin{tabular}{|c|c|c|c|c|}
\hline \multirow[b]{2}{*}{ Série de curso } & \multicolumn{2}{|c|}{ Ciências Contábeis } & \multicolumn{2}{|c|}{ Economia Empresarial e Controladoria } \\
\hline & $\mathbf{F i}$ & Fi (\%) & $\mathbf{F i}$ & Fi (\%) \\
\hline $1^{\circ}$ & 28 & $35,00 \%$ & 41 & $41,00 \%$ \\
\hline $2^{\circ}$ & 24 & $30,00 \%$ & 29 & $29,00 \%$ \\
\hline $3^{\circ}$ & 10 & $12,50 \%$ & 18 & $18,00 \%$ \\
\hline $4^{\circ}$ & 10 & $12,50 \%$ & 08 & $8,00 \%$ \\
\hline $5^{\circ}$ & 07 & $8,75 \%$ & 02 & $2,00 \%$ \\
\hline Não informou & 01 & $1,25 \%$ & 02 & $2,00 \%$ \\
\hline TOTAL & 80 & $100,00 \%$ & 100 & $100,00 \%$ \\
\hline
\end{tabular}

Fonte: dados da pesquisa.

Percebe-se, portanto, que a amostra deste estudo está composta por alunos representativos dos dois gêneros, predominantemente, jovens (entre 20 e 25 anos), com maior concentração de respondentes nos $1^{\circ}$ e $2^{\circ}$ anos dos dois cursos.

\subsection{Análise Descritiva}

A partir das questões que compõem a segunda parte do questionário apresenta-se na tabela 4 a frequência absoluta e relativa das respostas mais relevantes, permitindo a análise descritiva dos dados obtidos.

Tabela 4 - Frequência das respostas mais relevantes em cada variável

\begin{tabular}{|c|c|c|c|c|c|}
\hline \multirow[t]{2}{*}{ Constructos } & \multirow[t]{2}{*}{ Variáveis } & \multicolumn{2}{|c|}{ Ciências Contábeis } & \multicolumn{2}{|c|}{$\begin{array}{c}\text { Economia Empresarial e } \\
\text { Controladoria }\end{array}$} \\
\hline & & $\mathbf{F i}$ & Fi (\%) & $\mathbf{F i}$ & Fi (\%) \\
\hline \multirow{4}{*}{ Didática } & Clareza & 64 & $80 \%$ & 76 & $76 \%$ \\
\hline & Dinâmica & 15 & $19 \%$ & 07 & $7 \%$ \\
\hline & Metodologias & 19 & $24 \%$ & 26 & $26 \%$ \\
\hline & Interligação & 17 & $21 \%$ & 20 & $20 \%$ \\
\hline \multirow{4}{*}{ Conhecimento } & Prático & 20 & $25 \%$ & 18 & $18 \%$ \\
\hline & Específico & 45 & $56 \%$ & 63 & $65 \%$ \\
\hline & Amplo & 04 & $5 \%$ & 06 & $6 \%$ \\
\hline & Geral & 08 & $10 \%$ & 14 & $14 \%$ \\
\hline \multirow{4}{*}{ Experiência } & Desvinculada & 07 & $9 \%$ & 01 & $1 \%$ \\
\hline & Vinculada & 12 & $15 \%$ & 04 & $4 \%$ \\
\hline & Aproximação & 36 & $45 \%$ & 51 & $51 \%$ \\
\hline & Aplicação & 41 & $52 \%$ & 43 & $43 \%$ \\
\hline
\end{tabular}




\begin{tabular}{|c|c|c|c|c|c|}
\hline \multirow[t]{2}{*}{ Constructos } & \multirow[t]{2}{*}{ Variáveis } & \multicolumn{2}{|c|}{ Ciências Contábeis } & \multicolumn{2}{|c|}{$\begin{array}{c}\text { Economia Empresarial e } \\
\text { Controladoria }\end{array}$} \\
\hline & & Fi & Fi (\%) & $\mathbf{F i}$ & Fi (\%) \\
\hline \multirow{4}{*}{ Relacionamento } & Tolerância & 27 & $34 \%$ & 37 & $37 \%$ \\
\hline & Acessível & 34 & $44 \%$ & 57 & $57 \%$ \\
\hline & Ajudar & 39 & $49 \%$ & 56 & $56 \%$ \\
\hline & Flexível & 20 & $25 \%$ & 33 & $33 \%$ \\
\hline \multirow{5}{*}{ Postura } & Ético & 53 & $66 \%$ & 61 & $61 \%$ \\
\hline & Comprometido & 48 & $62 \%$ & 57 & $58 \%$ \\
\hline & Organizado & 42 & $53 \%$ & 46 & $47 \%$ \\
\hline & Proativo & 24 & $30 \%$ & 31 & $31 \%$ \\
\hline & Comunicativo & 39 & $49 \%$ & 49 & $49 \%$ \\
\hline
\end{tabular}

Fonte: dados da pesquisa.

Observa-se, pela Tabela 4, que as cinco competências requeridas dos docentes do curso de Ciências Contábeis consideradas mais importantes, na opinião dos discentes, foram clareza (80\%), ético (66\%), comprometido (62\%), conhecimento específico (56\%) e organizado (53\%). Para os alunos do curso de Economia Empresarial e Controladoria (ECEC) as cinco competências mais importantes foram clareza (76\%), conhecimento específico (65\%), ético (61\%), comprometido (58\%) e acessível (57\%).

Nota-se que das cinco competências mais importantes, quatro são comuns aos dois grupos de alunos, e que, as duas não citadas por ambos também são consideradas altamente importante para um percentual expressivo de alunos, sendo "acessível" assinalada por 44\% dos alunos de Ciências Contábeis e organizado por 47\% dos alunos do curso ECEC.

A competência apontada pelos dois grupos de alunos como sendo a de maior relevância em um bom professor foi a clareza. Esse resultado é semelhante aos resultados encontrados por Kühl et. al, (2013), Catapan, Colauto e Silas (2012), Vasconcelos (2010), Gomes et. al (2009), Araujo e Santana (2008) e Lowman (2007).

Catapan, Colauto e Silas (2012) e Gomes et. al (2009) utilizaram em seus estudos o Modelo Bidimensional desenvolvido por Lowman (2007) e como conclusão apontaram o atributo “claro" como sendo um dos mais importantes no perfil de um bom professor.

Além disso, ser comprometido e organizado são duas competências também apontadas, nos estudos desenvolvidos por Catapan, Colauto e Silas (2012), Gomes et al (2009), aos docentes exemplares de contabilidade, apoiando os resultados encontrados no presente estudo.

Conforme explica Lowman (2007), quando um professor é organizado, o conteúdo é extremamente bem organizado e apresentado em uma linguagem clara, assim como o relacionamento entre conceitos específicos e aplicações a novas situações são enfatizados. O impacto desse atributo nos alunos é um maior entendimento do objetivo traçado pelo professor, bem como aonde esse quer chegar.

Outra competência apontada pelos alunos, dos dois cursos, como sendo altamente importante diz respeito ao conhecimento específico apresentado pelo bom professor. Miranda, Casa Nova, Cornacchione Jr. (2012) encontraram em seu estudo o domínio do conteúdo como um dos saberes que caracterizam um professor-referência no ensino de contabilidade, tendo sido apontado por $53 \%$ dos alunos. Segundo os alunos, esses professores "demonstram o domínio do conteúdo exposto e o preparo nas respostas de questionamentos em aula, bem como discussões e reflexões que incitam". Eles são referências "por demonstrarem conhecimento bastante apurado nas disciplinas e por saberem passar com clareza os seus conhecimentos aos alunos".

Esse resultado reforça os achados de Nogueira, Casa Nova e Carvalho (2012), os quais concluíram, em seu estudo, que quando analisadas individualmente, as características mais valorizadas pelos estudantes da geração Y são: ter domínio do conteúdo e capacidade de explicá-lo claramente. Complementar a esse resultado estão as conclusões do estudo desenvolvido por Catapan, Colauto e Silas (2012), os quais ratificam que independente da geração do aluno, na visão dos alunos, ter domínio do conteúdo que ensina e transmitir de forma que se aprenda são características fundamentais em um bom professor.

O conhecimento do conteúdo específico da disciplina sempre foi considerado um requisito fundamental para qualquer professor, inclusive para o seu ingresso como docente na universidade. Estudos apontam que o domínio do conteúdo é a característica que melhor define o bom desempenho do docente (CATAPAN; COLAUTO; SILLAS, 2012; VASCONCELOS, 2000). Porém, conhecer o conteúdo a ser ministrado é diferente de ser capaz de apresentá-lo com clareza (LOWMAN, 2007), ou seja, apenas ter domínio do conteúdo específico não é suficiente para se ter um bom desempenho docente. 
A seguir, com o objetivo de identificar os fatores que melhor explicam ou estão associados à satisfação docente, aplicou-se a Análise Fatorial.

\subsection{Análise Fatorial}

Além da análise descritiva dos dados, aplicou-se a Análise Fatorial (AF), que permite sintetizar uma grande variedade de dados, visando detectar fatores comuns (FÁVERO et at, 2009). A partir da AF foi possível identificar fatores considerando-se o critério utilizado (autovalor>1), conforme demonstrado na Tabela 5. Sendo a variância total explicada pelos seis fatores de $58,75 \%$, o que indica que em torno de $59 \%$ da variação dos dados pode ser explicada pela utilização desta técnica.

Tabela 5 - Variância total explicada pela Análise Fatorial

\begin{tabular}{cccc}
\hline \multicolumn{3}{c}{ Autovalores } \\
\hline Componentes & Total & \% variância explicada & \% variância acumulada \\
\hline 1 & 4,62 & 22,00 & 22,00 \\
2 & 2,52 & 11,98 & 33,98 \\
3 & 1,76 & 8,40 & 42,38 \\
4 & 1,22 & 5,80 & 48,18 \\
5 & 1,15 & 5,47 & 53,65 \\
\hline
\end{tabular}

Fonte: dados da pesquisa.

Na Tabela 6 pode-se identificar os fatores e suas correspondentes cargas fatoriais, realizados pelo método de rotação Varimax padronizado.

Tabela 6 - Variáveis analisadas e os respectivos valores das cargas fatoriais

\begin{tabular}{|c|c|c|c|c|c|c|}
\hline \multirow{2}{*}{ Variáveis } & \multicolumn{6}{|c|}{ Cargas fatoriais } \\
\hline & 1 & 2 & 3 & 4 & 5 & 6 \\
\hline Ter disponibilidade e interesse em ajudar (V15) & 0,892 & & & & & \\
\hline $\begin{array}{l}\text { Utilizar em sala de aula exemplos concretos de aplicações práticas de } \\
\text { conceitos teóricos (V12) }\end{array}$ & & 0,924 & & & & \\
\hline $\begin{array}{l}\text { Ter amplo conhecimento das outras disciplinas relacionadas á discipli- } \\
\text { na ministrada (V7) }\end{array}$ & & & 0,954 & & & \\
\hline Demonstrar comprometimento com a atividade docente (V18) & & & & 0,933 & & \\
\hline Apresentar conteúdos de forma clara e objetiva (V1) & & & & & 0,983 & \\
\hline $\begin{array}{l}\text { Utilizar formas dinâmicas de aprendizagem, que promovam a partici- } \\
\text { pação do aluno (V2) }\end{array}$ & & & & & & 0,950 \\
\hline
\end{tabular}

Fonte: dados da pesquisa.

O fator que explica a maior parte da percepção discente (22\%) frente às competências do perfil de um bom professor foi o Fator 1, Ajudar, pertencente ao constructo Relacionamento. O Fator 2, Aplicação, explicou aproximadamente $12 \%$ da percepção discente e está associado ao constructo Experiência. O Fator 3, Amplo, referente ao amplo conhecimento docente, explicou 8,4\% e está associado ao constructo Conhecimento. O Fator 4, Comprometido, trata do comprometimento docente, explicou $5,8 \%$ e se relaciona ao constructo Postura. Os dois últimos fatores se referem ao 
constructo Didática, sendo que o Fator 5, Clareza, explicou 5,47\% e o Fator 6, Dinâmica, explicou 5,10\% da percepção dos discentes.

Corroborando com os resultados encontrados pela aplicação da AF, os fatores clareza ( $80 \%$ e $76 \%$ ), aplicação do conteúdo ( $52 \%$ e $43 \%$ ), ajudar ( $49 \%$ e $56 \%$ ) e comprometido ( $62 \%$ e $58 \%$ ) foram indicados como altamente importantes por uma alta percentagem dos alunos dos cursos de Ciências Contábeis e ECEC, respectivamente.

Como salientado anteriormente, ser claro ao expor os conteúdos e estar comprometido com a docência são duas competências consideradas de extrema importância no perfil do bom professor, sendo apontado por autores como Kühl et. al, (2013), Catapan, Colauto e Silas (2012), Vasconcelos (2010), Gomes et. al (2009), Araujo e Santana (2008) e Lowman (2007).

É importante ressaltar que as variáveis Dinâmica (Utilizar formas dinâmicas de aprendizagem, que promovam a participação do aluno) e Amplo conhecimento (Ter amplo conhecimento das outras disciplinas relacionadas à disciplina ministrada) apontaram baixa frequência de respostas do tipo altamente importante pelos alunos, sendo $7 \%$ e $19 \%$, e $6 \%$ e $5 \%$, respectivamente, pelos alunos dos cursos de Ciências Contábeis e ECEC, respectivamente. Esses resultados podem indicar que, para os alunos destes cursos, os docentes de contabilidade não utilizam essas competências em sala de aula.

\section{CONSIDERAÇÕES FINAIS}

Este estudo teve como objetivo analisar quais competências são consideradas mais importantes no perfil de um bom professor de Contabilidade na ótica discente a partir da percepção de alunos dos cursos de Ciências Contábeis e Economia Empresarial e Controladoria (ECEC)

O estudo conta com a percepção de 180 alunos que responderam de forma válida a um questionário aplicado. $O$ questionário, baseado nos estudos de Pereira (2007) e Külh et al (2013), era composto por 21 assertivas sobre cinco competências docentes: Didática; Conhecimento; Experiência; Relacionamento; e Postura. O respondente se posicionava sobre a importância de cada assertiva por meio de uma escala Likert de cinco pontos, sendo 5 a posição de maior importância.

Dentre as competências apresentadas por meio das assertivas, destacam-se quatro: apresentar conteúdos de forma clara e objetiva (Didática); possuir profundo conhecimento da disciplina em que atua (Conhecimento); demonstrar postura ética (Postura); e demonstrar comprometimento com a atividade docente (Postura). Os quatro foram atributos apontados como sendo altamente importante por mais de $50 \%$ dos discentes de ambos os cursos participantes. Esses atributos pertencem aos constructos Didática, Conhecimento e Postura. Esse resultado reforça os achados por Gomes et al (2009), que em seu estudo apontaram as competências: estar preparado, ser claro, organizado e estimular os alunos. E também reforça o estudo de Swain e Stout (2000), no qual os autores concluem que as competências organização do currículo e planejamento da ação educativa e comunicação do conteúdo foram elencadas como as mais importantes para doutores recém titulados.

De forma complementar, a análise fatorial permitiu identificar seis fatores associados à percepção dos discentes frente às competências dos docentes no que se refere às características do "bom professor". O fator pertinente ao constructo Relacionamento foi o que apresentou maior porcentagem da variância explicada (22\%), indicando a importância da disponibilidade e interesse do docente em ajudar. O segundo fator foi utilizar em sala de aula exemplos concretos de aplicações práticas de conhecimentos teóricos, ligado ao constructo Experiência. O terceiro fator é ter amplo conhecimento, ligado ao constructo Conhecimento. O quarto fator é demonstrar comprometimento com a atividade docente, relativo ao construto Postura. O quinto e o sexto fator estão ligados ao construto Didática, são eles: apresentar conteúdos de forma clara e objetiva, e utilizar formas dinâmicas de aprendizagem, que promovam a participação do aluno. Esses resultados são similares ao estudo de Rezende e Leal (2013), que apontaram que as competências que possuem maior relevância estão relacionadas ao domínio do conhecimento, à didática e à experiência de mercado.

Ao analisar de forma conjunta a estatística descritiva e a análise fatorial, os atributos que se destacam em ambas são relativos ao constructo Didática e Postura, sendo eles: apresentar conteúdos de forma clara e objetiva; e demonstrar comprometimento com a atividade docente.

Diversos estudos em âmbito nacional e internacional demonstram a importância da formação pedagógica para o docente no ensino superior, tanto na sua formação inicial quanto continuada. Assim, considera-se que os fatores identificados neste estudo podem contribuir para melhorias na área do ensino, visto que podem ser promovidas ações de melhorias relacionadas a fatores que não tiveram muito destaque nesta pesquisa. Destaca-se que o tamanho da amostra pode ter contribuído para não identificação de mais variáveis dentro dos respectivos fatores.

Cabe ressaltar, dessa forma, que uma limitação deste estudo diz respeito à amostra, uma vez que se ateve a investigar a perspectiva dos discentes dos dois cursos de uma universidade pública. Como sugestão para futuras pesquisas, recomenda-se a replicação deste estudo com uma amostra maior e diversificada, onde pode ser incluído o grupo de discentes de pós-graduação, bem como de alunos da graduação de cursos correlatos, como Administração e Economia.

\section{REFERÊNCIAS}

AMARAL, A. L. Significados e Contradições nos processos de formação de professores. In: Convergência e tensões no campo da formação e do trabalho docente: didática, formação de professores, trabalho docente, DALBEN, A.; DINIZ, J.; LEAL, L.; SANTOS, L. (Org). Belo Horizonte: Autêntica, 2010. 
ANDERE, M. A.; ARAUJO, A. M. P. de. Aspectos da formação do professor de ensino superior de ciências contábeis: uma análise dos programas de pós-graduação. Revista Contabilidade \& Finanças, v. 19, n.48, p. 91-102, 2008.

ARAUJO, M. D. C.; SANTANA, C. M. Análise das percepções e expectativas dos alunos de ciências contábeis na universidade de Brasília quanto ao perfil do professor e inserção no mercado de trabalho. In: Congresso USP de Controladoria e Contabilidade, 8, 2008, São Paulo. Anais do XIII Congresso USP de Controladoria e Contabilidade, São Paulo: SP, 2008.

BOULEY, F; WUTTKE, E.; SCHNICK-VOLLMER K.; SCHMITZ, B.; BERGER S.; FRITSCH, S.; SEIFRIED, J. Professional Competence of Prospective Teachers in Business and Economics Education: Evaluation of a Competence Model Using Structural Equation Modeling, Peabody Journal of Education, v. 90, n.4, p. 491-502, 2015.

BRASLAVSKY, C. Bases, orientaciones y criterios para el diseño de programas de formación de professiores. Revista Iberoamericana de Educación, 19, p. 13-50, 1999.

CATAPAN, A.; COLAUTO, R. D.; SILLAS, E. P. (2012). Percepção dos discentes sobre os docentes exemplares de contabilidade em IES públicas e privadas. Revista de Informação Contábil, v. 6, n. 2, p. 63-82.

CELERINO, S.; PEREIRA, W. F. C. Atributos e prática pedagógica do professor de contabilidade que possui êxito no ambiente universitário: visão dos acadêmicos. Revista Brasileira de Contabilidade, v. 37, n. 170, p. 65-77, 2008.

COSTA, F. J.; MOREIRA, J. A.; ETHUR, S. Z. O perfil dos professores de pós-graduação em administração na perspectiva dos alunos. In: Encontro da Associação Nacional de Pós-Graduação e Pesquisa em Administração, 30, 2006, Salvador. Anais do XXX Encontro da Associação Nacional de Pós-Graduação e Pesquisa em Administração, Salvador: BA, 2006.

CUNHA, M. I. O bom professor e sua prática. 6. ed. Campinas: Papirus. 1992.

DIAS, I. S. Competências em educação: conceito e significado pedagógico. Revista Semestral da Associação Brasileira de Psicologia Escolar e Educacional, v. 14, n. 1, p. 73-78, 2010.

GOMES, M. E. M.; ALBUQUERQUE, L. S.; CARVALHO, J. R. M.; SANTIAGO, J. S.; LUCENA, W. G. L. \& RÊGO, T. F. Atributos e práticas pedagógicas do professor de contabilidade que possui êxito em sala de aula: estudo da percepção discente em IES Públicas. In Encontro de Ensino e Pesquisa em Administração e Contabilidade, 2, 2009, Curitiba. Anais do II Encontro de Ensino e Pesquisa em Administração e Contabilidade, Curitiba: PR, 2009.

GRADVOHL, R. F; LOPES, F. F. P.; COSTA, F. J. O perfil do bom professor de contabilidade: uma análise a partir da perspectiva de alunos de cursos de graduação. Anais do Congresso USP de Controladoria e Contabilidade, São Paulo, SP, Brasil, 9, 2009.

HORA, H. R. M.; MONTEIRO, G. T. R.; ARICA, J. Confiabilidade em questionários para qualidade: um estudo com o coeficiente alfa de cronbach. Produto e produção, v. 11, n. 2, p. 85-103, 2010.

KÜHL, M. R.; MAÇANEIRO, M. B.; CUNHA, J. C.; CUNHA, S. K. O valor das competências docentes no ensino da Administração. Revista de Administração, 4, p. 783-799, 2007.

LOWMAN, J. Dominando as técnicas de ensino. 1. ed. São Paulo: Atlas, 2007.

MARQUES, V. A.; OLIVEIRA, M. C.; NASCIMENTO, E. M.; CUNHA, J. V. A. Atributos de um bom professor: um estudo sobre a percepção dos alunos de ciências contábeis. Revista de Contabilidade e Controladoria, v. 4, n. 2, p. 7-23, 2012.

MASETTO, M. T. Competência pedagógica do professor universitário. 2 ed. São Paulo: Summus. 2012.

MEDEIROS, A. C. P.; OLIVEIRA, L. M. B. Análise das competências de ensino relevantes ao bom desempenho docente: um estudo de caso. In: Encontro da Associação Nacional de Pós-Graduação e Pesquisa em Administração, 33, 2009, São Paulo. Anais do XXXIII EnANPAD, São Paulo: SP, 2009

MIRANDA, G. J. Docência universitária: uma análise das disciplinas na área da formação pedagógica oferecidas pelos programas de pós-graduação stricto sensu em Ciências Contábeis. Revista de Educação e Pesquisa em Contabilidade, v. 4, n. 2, p. 81-98, 2010.

MIRANDA, G. J.; CASA NOVA, S. P. D. C.; CORNACCHIONE JÚNIOR, E. B. Os saberes dos professores-referência no ensino de contabilidade. Revista Contabilidade \& Finanças, v. 23, n. 59, p. 142-153, 2012.

NOGUEIRA, D. R.; CASA NOVA, S. P. D. C.; CARVALHO, R. C. O. O bom professor na perspectiva da geração Y: uma análise sob a percepção dos discentes de Ciências Contábeis. Enfoque: Reflexão Contábil, v. 31, n. 3, p. 37-52, 2012.

OTT, E.; CUNHA, J. V. A.; CORNACCHIONE JR., E. B.; DE LUCA, M. M. M. Relevância dos conhecimentos, habilidades e métodos instrucionais na perspectiva de estudantes e profissionais da área contábil: estudo comparativo internacional. Revista Contabilidade e Finanças, v.22, n. 57, p. 338-356, 2011.

PAN, D.; TAN, G. S. H.; RAGUPATHI, K.; BOOLUCK, K.; ROOP, R.; IP, Y. K. Profiling Teacher/Teaching Using Descriptors Derived from Qualitative Feedback: Formative and Summative Applications. Research High Education, v. 50, n. 1, p. 73-100, 2009.

PASQUALI, L. Psicometria: teoria dos testes na psicologia e na educação. Petrópolis: Vozes, 2003.

PEREIRA, M. A. C. Competências para o ensino e a pesquisa: um survey com docentes de engenharia química. 2007. Tese (Doutorado em Engenharia de Produção) - Escola Politécnica, Universidade de São Paulo, São Paulo, 2007.

PERRENOUD, P. 10 novas competências para ensinar. Porto Alegre: ArtMed. 2010.

PIMENTA, S. G. A didática como mediação na construção da identidade do professor: uma experiência de ensino e pesquisa na Licenciatura. Campinas: Papirus. 1997.

PLUTARCO, F. F.; GRADVOHL, R. F. Competências dos professores de administração: a visão dos alunos de cursos de graduação. In: Encontro da Associação Nacional de Pós-Graduação e Pesquisa em Administração, 34, 2010, Rio de Janeiro. Anais do XXXIV EnANPAD, Rio de Janeiro: RJ, 2010. 
RALDI, D. P.; MALHEIROS, C. F; FRÓIS, I. M.; LAGE-MARQUES, J. L. O papel do professor no contexto educacional sob o ponto de vista dos alunos. Revista da ABENO, v. 3, n. 1, p. 15-23, 2003.

REICHEL, N; ARNON, S. A Multicultural view of the good teacher in Israel. Teachers and Teaching: theory and practice, v. 15, n. 1, p. 59-85, 2009.

REZENDE, M. G.; LEAL, E. A. Competências requeridas dos docentes do curso de Ciências Contábeis na percepção dos estudantes. Sociedade, Contabilidade e Gestão, v. 8, n. 2, p. 145-160, 2013.

REZENDE, J. L. Q.; SOUZA, A. A.; MIRANDA, G. J.; LEAL, E. A. Competências didáticas dos professores de cursos de MBAs. Revista de Contabilidade da UFBA, v. 9, n. 2, p. 05-18, 2015.

SELVI, K. Teachers' competencies. Cultura: International Journal of Philosophy of Culture and Axiology, v. 7, n. 1, p. 167-175, 2010.

SLOMSKI, V. G. Saberes que fundamentam a prática pedagógica do professor de Ciências Contábeis. In: Congresso USP de Controladoria e Contabilidade, 8, 2008, São Paulo. Anais do VIII Congresso USP de Controladoria e Contabilidade, São Paulo: SP, 2008.

SWAIN, M. R.; STOUT, D. E. Survey evidence of teacher development based on AECC recommendations. Journal of Accounting Education, v. 18, p. 99-113, 2000.

TOLENTINO, J. E. F; SILVA, R. M. P.; COSTA, A. J. B.; ARAUJO NETO, L. M. O perfil esperado de um professor de contabilidade: uma análise a partir dos estudantes da cidade de Barcelos - Portugal. Revista Catarinense da Ciência Contábil, v. 13, n. 39, p. 09-20, 2014.

TORRA, I.; DE CORRAL, I.; PÉREZ, M. J.; TRIADÓ, X.; PAGÈS, T.; VALDERRAMA, E.; MÀRQUEZ, M. D.; SABATÉ, S.; SOLÀ, P.; HERNÀNDEZ, C.; SANGRÀ, A.; GUÀRDIA, G.; ESTEBANELL, M.; PATIÑO, J.; GONZÁLEZ, A.; FANDOS, M.; RUIZ, N.; IGLESIAS, M. C.; TENA, A. Identificación de competencias docentes que orienten el desarrollo de planes de formación dirigidos a profesorado universitario. REDU - Revista de Docencia Universitaria, v. 10, n. 2, p. 21-56, 2012.

VASCONCELOS, M. L. M. C. A formação do professor do ensino superior. 2. ed. São Paulo: Pioneira. 2000.

VASCONCELOS, A. D. Fatores que influenciam as competências em docentes de ciências contábeis. In: Encontro da Associação Nacional de Pós-Graduação e Pesquisa em Administração, 34, 2010, Rio de Janeiro. Anais do XXXIV EnANPAD, Rio de Janeiro:RJ, 2010.

VOLPATO, G. Marcas de profissionais liberais que se tornaram professores-referência. Revista Brasileira de Estudos Pedagógicos, v. 90, n. 225, p. 333-351, 2009. 